\title{
A INSUSTENTÁVEL RESPOSTA DA “CRIMIGRAÇÃO” FACE À IRREGULARIDADE DOS MIGRANTES: UMA PERSPETIVA DA UNIÃO EUROPEIA
}

\author{
Maria João Guia ${ }^{1}$ \\ João Pedroso ${ }^{2}$
}

\begin{abstract}
A condição jurídica de "Irregular" dos imigrantes na entrada e na permanência, em determinado país, é uma decisão de cada um dos Estados, que escolhem entre criminalizar e proibir esses comportamentos ou os integrar e "regularizar", permitindo o seu acesso a (alguns) direitos dos nacionais. Nos últimos anos vários Estados dos EUA enveredaram por uma política pública de "crimigração" fazendo convergir a lei criminal com a lei de imigração com o objetivo de punir e expulsar os imigrantes "construídos" como irregulares. Na Europa também têm sido implementadas recentemente políticas, direito e práticas "crimigratórias" transplantadas dos EUA. No entanto, países como Portugal acolhem moderadamente essa tendência, continuando a optar preferencialmente pela inclusão e por uma legislação de "regularização permanente" dos imigrantes.
\end{abstract}

Palavras-chave: irregularidade, imigrantes, crimigração, criminalização, inclusão.

\section{Introdução ${ }^{3}$}

A necessidade do debate acerca da emigração e imigração, na Europa, intensificou-se nos últimos anos ${ }^{4}$. Alguns países estão sujeitos a grandes pressões resultantes de uma imigração crescente $^{5}$ e as estimativas apontam para a

1 Centro de Direitos Humanos da Faculdade de Direito da Universidade de Coimbra. Coimbra, Portugal.

2 Centro de Estudos Sociais (CES), DECIDe - Núcleo da Democracia, Cidadania e Direito. Coimbra, Portugal.

3 Este artigo resulta de uma reflexão conjunta dos autores a partir de GUIA, Maria João. Imigração, 'Crimigração' e Crime Violento. Os Reclusos estrangeiros e as representações sobre imigração e Crime.

4 PEIXOTO, João. A imigração em Portugal, demografia e dinâmicas.

5 As estimativas mostram que $15 \%$ dos imigrantes a viver na União Europeia e $30 \%$ dos que entram todos os anos o fazem irregularmente (cf. Migration News). O problema das pressões migratórias foi 
existência de milhões de imigrantes irregulares, que há muito tempo se resignaram à sobrevivência na Europa Ocidental e nos Estados Unidos da América. Com efeito, nos últimos 20 anos, vários países da União Europeia receberam grandes vagas de imigrantes, oriundos maioritariamente de países pobres de continentes como Ásia, África e América do Sul. Em 2014, a maior parte dos indivíduos detetados em irregularidade na UE eram oriundos da Síria, Eritreia e Afeganistão, sendo que estas 3 nacionalidades constituíam um terço do total ${ }^{6}$. Na verdade, e segundo Barbagli ${ }^{7}$, desde a altura em que os países da Europa abrandaram a absorção de mão-de-obra migrante, as únicas formas de atravessar as fronteiras têm sido através dos pedidos de asilo ou da imigração irregular.

As recentes medidas mais restritivas quanto à entrada de imigrantes no espaço europeu têm vindo a provocar o efeito perverso do favorecimento da sua entrada irregular ${ }^{8}$, acabando por se verem colocados em situação de exclusão permanente no que concerne a apoios sociais, acesso à saúde e à educação. Labbens $^{9}$ havia já invocado, relativamente aos imigrantes, o que conhecemos como a "célebre trilogia webberiana"10 ao afirmar que "para ser pobre, é necessária a falta simultânea da fortuna e da ocupação remunerada (classe), da força social (poder) e da responsabilidade (estatuto)". Engbersen ${ }^{11}$ apelidou este espaço de "Europa Panóptica", não tanto pela vertente foucaultiana da "correção de comportamentos", mas pelo seu caráter de "fábrica de exclusão" de "pessoas habituadas ao seu estatuto de excluídos"12.

Neste artigo, começaremos por refletir sobre a questão da irregularidade e, de seguida, o modo como as "mutações" do Estado alteram as políticas de gestão das migrações irregulares. Por último, abordaremos as perspetivas da irregularidade de migrantes na esfera da emergência da 'crimigração' nos Estados Unidos da América (EUA) e na União Europeia (UE), num contexto "insuflado por um alvoroço securitário contemporâneo, sobre as garantias e as liberdades individuais"13.

analisado pelo Conselho Europeu, reunido em Edimburgo em 1992, que decidiu "reforçar as suas tentativas comuns para combater a imigração ilegal".

6 SABBATI, Giulio, POPTCHEV, Eva-Maria. Irregular immigration in the EU: Facts and Figures. Briefing, p. 3.

7 BARBAGLI 1998 apud KILLIAS, Martin. Immigration and Crime: The European Experience. Improving US and EU Immigration Systems, p. 5.

8 Enquanto a força laboral do trabalho dos imigrantes for rentável para as economias de cada Estado, este continuará a ser permissivo na estadia de migrantes, desde que eles não levantem problemas graves (GIL-ROBLES, Alvaro. Report by Mr Alvaro Gil-Robles, Commissioner for Human Rights on his visit to Portugal, 27-30 Maio 2003).

9 LABBENS, Jean. Le Quart-Monde, étude sur la condition sous-prolétarienne.

${ }^{10}$ ETIENNE, Jean et alii. Dicionário de Sociologia.

${ }^{11}$ ENGBERSEN, Godfried. The unanticipated consequences of panopticon Europe. Residence strategies of illegal immigrants.

12 Ibidem, p. 242.

${ }^{13}$ CAEIRO, Pedro. Alguns aspectos do Estatuto de Roma e os reflexos da sua ratificação na proibição constitucional de extraditar em caso de prisão perpétua, p. 58. 


\section{Da (des)construção da (i)rregularidade à "crimigração"}

"Devia ter ido lá fazer um discurso, mas, com o meu sotaque, temi que me expulsassem" (Arnold Schwarzenegger, 2010 ${ }^{14}$ ).

Robert Koulish ${ }^{15}$ analisa a viragem no discurso e no tratamento dos imigrantes em situação irregular nos EUA, baseado na "sociedade de risco", mudando o enfoque da prevenção da entrada para a gestão e o controlo social destas populações quando elas já se encontram dentro do território americano ${ }^{16}$. A entrada de imigrantes é impossível de impedir através dos instrumentos legais, pelo que deixa de ser entendida como um risco eliminável, para passar a ser um risco passível de ser gerido. As narrativas adotadas, neste contexto, estabelecem associações entre a imigração e perigos de catástrofe global e transfronteiriça, permitindo desse modo a criminalização da circulação desses indivíduos ${ }^{17}$. De acordo com o autor, este discurso permite, ainda, formas de controlo social que vão muito além da criminalização, recorrendo às novas tecnologias da informação e à biométrica como forma de controlo social. O discurso do risco aplicado à imigração irregular é polissémico: esta constitui um risco à soberania do Estado Nação - "à integridade territorial" - no sentido em que as populações em situação irregular são ingovernáveis, e constitui igualmente um risco para elas mesmas e para o resto da comunidade - por exemplo, as consequências advindas da falta de acesso a cuidados de saúde básicos ${ }^{18}$.

Com efeito, os imigrantes em situação irregular ficam desprovidos de qualquer estatuto jurídico e de cidadania, o que facilita a subjugação de, muitos deles, a organizações, por vezes criminosas, que operam transnacionalmente. Eles caem nas redes criminosas procurando melhores condições de vida e o acesso a cuidados mínimos de saúde, educação e trabalho. Paradoxalmente, a atividade destas organizações acaba por ser estimulada pelos Estados industrializados, que são permissivos na utilização de mão-de-obra barata, face às necessidades que não conseguem suprir, descurando muitas vezes as condições de vida e estatuto de cidadania dos imigrantes.

\subsection{A "crimigração" como resposta à irregularidade}

A 'crimigração' é uma teoria que tem vindo a ser construída desde $2006^{19}$ originária dos Estados Unidos da América (EUA) desde a década de 80, do século

\footnotetext{
${ }^{14}$ Arnold Schwarzenegger, governador republicano da Califórnia, de origem austríaca, a propósito da aplicação da lei anti-imigração votada pelo estado do Arizona. The Atlanta Journal-Constitution, Estados Unidos da América. Cf. Courier Internacional, n. 173, julho de 2010, p. 18.

${ }^{15} \mathrm{KOULISH}$, Robert. Entering the risk society: A contested terrain for immigration enforcement.

${ }^{16}$ Ibidem, p. 62.

17 Especialmente a partir do 11 de setembro de 2001. Ibidem, p. 63.

18 AGUILERA, 2012 apud KOULISH, op. cit., p. 64.

${ }^{19}$ STUMPF, Juliet. The Crimmigration Crisis: Immigrants, Crime \& Sovereign Power.
} 
$X X$, com uma implementação recente na Europa ${ }^{20}$. O argumento central desta teoria assenta na perda progressiva de direitos dos migrantes e, em simultâneo, na criminalização crescente dos comportamentos dos mesmos, com a aplicação simultânea da lei penal a migrantes (que não cometeram crimes) e a aplicação da lei de imigração a condenados por crimes (com afastamento permanente dos territórios onde estes condenados cometeram os crimes). Stumpf ${ }^{21}$ caracterizou esta política como a convergência da Lei Penal com a Lei de Imigração, caracterizando-a pela elevada intransigência em relação aos indivíduos não nacionais, o que implica uma estratificação do acesso aos direitos, incluindo o direito de exercer a cidadania. Inicialmente, esta maior intolerância para com os estrangeiros infratores ou para com a irregularidade destinava-se a um conjunto de crimes violentos (homicídio, tráfico de droga e de armas), aos quais se foram juntando, ano após ano, outros crimes menores que passaram a ser motivo de expulsão e de interdição de entrada cada vez mais prolongadas ${ }^{22}$.

\subsection{EUA: o berço da "crimigração"}

A evolução histórica dos Estados Unidos da América explica muitos dos fatores relacionados com os movimentos migratórios do país, que é fruto de uma imigração massiva de cidadãos europeus e do domínio destes sobre os nativos, devendo, aliás, o seu desenvolvimento ao trabalho escravo e mais tarde ao trabalho imigrante. A partir dos anos oitenta, com o aumento da imigração irregular oriunda da Ásia e do México ${ }^{23}$, depois do colapso financeiro de $1983^{24}$ e do caso "Boatlif Mariel" em que o governo cubano encorajava os cubanos condenados a ir para o mar e tentar o pedido de asilo nos EUA ${ }^{25}$, a Lei Penal e a Lei da Imigração começaram a convergir, dando lugar à política pública da "crimigração".

A estratificação do acesso aos direitos, incluindo o direito de exercer a cidadania em pleno, e a acumulação de sanções penais e imigratórias, levou ao

\footnotetext{
${ }^{20}$ VAN DER LEUN, Joanne, VAN DER WOUDE, Maartje. Uma Reflexão Sobre a Crimigração na Holanda: O Complexo da Segurança Cultural e o Impacto do Enquadramento.

${ }^{21}$ STUMPF, op. cit.

${ }^{22}$ Os designados "aggravated felonies" implicavam inicialmente os crimes de homicídio, tráfico de droga e de armas. Em 1990, o Immigration Act redefiniu este grupo de crimes constantes no "aggravated felonies" para todos os crimes violentos condenados com penas superiores a 5 anos. Em 1995, foram acrescentados a este grupo de crimes outros não violentos (furtos, burlas, falsificações, prostituição, etc.). Em 1996, o grupo de crimes incluídos no "aggravated felonies" estendeu-se a todos os crimes condenados em pena de mais de um ano.

${ }^{23} \mathrm{E}$ mais recentemente com a ameaça dos ataques terroristas.

${ }^{24}$ Entre 1982 e 1988, a administração de Miguel de la Madrid Hurtado levou a cabo inúmeras reformas, liberalização do comércio e grandes contenções de gastos públicos. Mas a inflação subiu acima dos 100\%. O terremoto de 1985 ocorrido na Cidade do México e a queda do preço do petróleo em 1986 contribuíram da mesma forma para este cenário de catástrofe económica (KESSLER, Timothy. A Quebra do Peso Mexicano: Causas, Consequências e Recuperação).

${ }^{25}$ MILLER, Teresa. Citizenship \& Severity: Recent Immigration Reforms and the New Penology.
} 
aumento imediato das deportações ${ }^{26}$. A Lei da Imigração tem sido desde então aplicada a comportamentos que anteriormente eram objeto exclusivamente da Lei Penal. As ordens de expulsão passaram a incluir situações de irregularidade e condenações iguais ou superiores a 5 anos, que, por sua vez, passaram a abranger crimes não violentos e, posteriormente, estendeu-se a crimes cujas condenações não ultrapassavam um ano - o que engloba crimes não violentos e as "bagatelas penais". Além disso, o período de interdição de entrada nos EUA duplicou, assim como a detenção de cidadãos estrangeiros sem acusação, ao abrigo da lei antiterrorista. Neste contexto, o aumento das condenações e das ordens de expulsão a cidadãos estrangeiros constitui uma ferramenta de exclusão (implícita e explícita, respetivamente), refletindo escolhas políticas ${ }^{27}$.

A 'crimigração' 28 analisa, como se referiu, a convergência da lei criminal (penal) com a lei da imigração, concretizada através da existência da teoria da pertença ${ }^{29}$, problematizando a cidadania nos EUA, o que cataloga os migrantes em "insiders" e "outsiders", cingindo os indivíduos não-nacionais a sentimentos de inserção ou exclusão da sociedade. A teoria da pertença preconiza a permissão concedida aos membros do contrato social ${ }^{30}$ estabelecido entre o governo norteamericano e os indivíduos, restringindo a alguns o acesso a determinados direitos e privilégios e aventando explicações para tal exclusão. Quando a teoria da pertença está em causa, todo o âmbito de direitos constitucionais depende da perspetiva do decisor ${ }^{31}$, o que, segundo Demleitner ${ }^{32}$, resulta no esvaziamento da dignidade da pessoa humana como cidadão, ao sofrer as restrições sociais e políticas resultantes daquilo a que se designa por 'paradigma da crimigração'.

Esta conexão da lei de imigração com a lei penal implica, em primeiro lugar, uma exclusão física e, logo depois, a imposição de normas que estabelecem níveis estratificados de cidadania. A convergência da 'crimigração' implica também que, para um mesmo comportamento, possa haver sanções criminais (que resultam, normalmente, em reclusão) e as previstas na lei de imigração (normalmente a expulsão). As bases de dados dos estrangeiros passaram a estar disponíveis para as polícias, o que acabou por reforçar a lei de imigração que passou também a

\footnotetext{
${ }^{26}$ STUMPF, op. cit.

${ }^{27}$ Refira-se ainda que o período de interdição de entrada no país após estas deportações passou para um período de 10 a 20 anos, bem como as detenções dos chamados "não cidadãos" sem acusação, justificada por um "razoável período de tempo" que pode ir até 7 dias, sobretudo ao abrigo da lei antiterrorista.

${ }^{28}$ STUMPF, op. cit.

29 "Membership theory" no original (ibidem).

${ }^{30}$ A cidadania é definida por Aleinikoff como a "pertença a um Estado resultante de consentimento mútuo entre um indivíduo e um estado" (ALEINIKOFF, Alexander. Theories of Loss of Citizenship).

31 STUMPF, op. cit.

32 DEMLEITNER, Nora. Misguided Prevention: The War on Terrorism as a War on Immigrants Offenders and Immigration Violators.
} 
substituir a lei criminal, sobretudo fundamentando as detenções ou deportações dos supostamente envolvidos em ações terroristas ${ }^{33}$.

Para além disso, o Sistema Nacional de Segurança de Entradas e Saídas, o NSEERS ${ }^{34}$, a partir do 11 de setembro começou a exigir aos indivíduos "não-cidadãos" oriundos de determinados países árabes e muçulmanos que fizessem um registo no $\mathbb{I N S}^{35}$. Os condenados por crimes ou por violações à lei de imigração, de fé muçulmana e de etnia árabe, foram, inclusivamente, procurados, detidos e deportados, independentemente dos factos que thes tinham sido imputados, por estarem relacionados com atividades terroristas ${ }^{36}$. As leis de imigração, nestes casos concretos, foram usadas para deter e deportar indivíduos "não-cidadãos". Acresce que a raça/etnia e a nacionalidade de origem dos indivíduos passaram a ser condições humanas, que o Supremo Tribunal dos EUA considerou serem de relevo e justificativas para as operações stop de cidadãos efetuadas pela polícia ${ }^{37}$.

\section{A irregularidade e a emergência da "crimigração" na União}

\section{Europeia}

Existem cada vez mais turistas e estudantes que se deslocam ao estrangeiro $^{38}$, e cada vez mais trabalhadores a desenvolver projetos em Estadosmembros da UE, que não os seus. Adicionalmente, catástrofes, guerras e ataques terroristas têm levado à deslocação massiva de pessoas para a UE ${ }^{39}$, em busca de melhores condições de vida.

Mas nem todos os migrantes entram nos países de destino com os devidos documentos legais. As estimativas apontam para 2,5 a 4 milhões de migrantes irregulares que atravessam fronteiras internacionais todos os anos. O cálculo correspondente aos "stocks" de migrantes irregulares na Europa ${ }^{40}$ (UE) aponta para os 5 milhões (dentro dos 56,1 milhões que aí vivem), o que representa cerca de $10 \%$ dos migrantes na sua totalidade ${ }^{41}$.

33 STUMPF, op. cit.

${ }^{34}$ NSEERS - National Security Entry-Exit System, do inglês original.

${ }^{35}$ INS - Immigration and Naturalization Service, do inglês original.

${ }^{36}$ STUMPF, op. cit.

37 Ibidem, p. 25.

${ }^{38} \mathrm{O}$ número de migrantes dentro na nossa sociedade globalizada duplicou nos últimos 25 anos, atingindo os 213.943,8 milhões de migrantes que abandonaram os seus países de origem em 2010, um número considerável, segundo United Nations, Department of Economic and Social Affairs.

${ }^{39}$ Não obstante, é preciso não esquecer que mais de $96 \%$ da população mundial nasce, vive e morre no mesmo país, uma afirmação que contradiz a hipótese de que as migrações se encontrarem fora de controlo (PIRES, Rui. Atlas of Migrations).

${ }^{40}$ O cálculo de migrantes irregulares nos EUA (stocks) aponta para os 10,5 milhões (HOEFER, Michael et alii. Estimates of the Unauthorized Immigrant Population Residing in the United States: January 2006).

${ }^{41}$ Cf. RCMI. As Migrações num Mundo Interligado: Novas Linhas de Acção. Nos EUA, estima-se que cerca de 3,1 milhões desses 10,5 milhões de pessoas a residir sem autorização nesse espaço em 2005 tenham entrado depois do ano 2000. 


\subsection{Os imigrantes em irregularidade na UE: entre a inclusão e a criminalização}

Os fluxos migratórios irregulares têm sido entendidos como "indesejáveis" desde a proibição do recrutamento de imigrantes nos anos $70^{42}$. No início dos anos 90, estimou-se que existiam cerca de 2,6 milhões de imigrantes irregulares na Europa Ocidental ${ }^{43}$. A partir de 1980, muitos países optaram por implementar diversos programas de regularização de imigrantes ${ }^{44}$.

A forma como os Estados têm adotado medidas de combate à imigração irregular dentro dos Estados-Membros da UE é bastante diferente, especialmente entre os membros da Europa do Norte, que adotaram medidas de "dissuasão, exclusão e, em último caso, expulsão"45, e os países do sul ocidental (especialmente Portugal, Espanha, Itália e Grécia) que optaram pela via da regularização, no que foram acompanhados pela Bélgica e pela França ${ }^{46}$. Entre 1973 e 2008, foram conduzidos 68 programas de regularização nos Estadosmembros, tendo ocorrido 4,3 milhões de regularizações ${ }^{47}$. Mas o maior número de regularizações de migrantes teve lugar entre 1998 e 2008, um período em que foram implementados 40 programas de regularização na Europa e realizadas 3.268.860 regularizações, um valor que permite calcular a verdadeira dimensão deste fenômeno. Foi nos referidos países do Sul que os programas de maior escala para a regularização de migrantes em situação irregular ${ }^{48}$ foram implementados ${ }^{49}$. Kraler sublinha, entre outros fatores, a "alteração das normas de proteção internacional, o aumento das considerações em torno das normas dos direitos humanos no domínio da legislação de estrangeiros, e os lobbies extremamente fortes que existem na sociedade" ${ }^{\prime 50}$.

É ainda importante sublinhar que o alargamento da UE resultou na "regularização" de muitos cidadãos que anteriormente eram considerados

${ }^{42}$ CVAJNER, Martina, SCIORTINO, Giuseppe. A Tale of Networks and Policies: Prolegomena to an Analysis of Irregular Migration Careers and Their Developmental Paths.

${ }^{43}$ CASTLES, Stephen, MILLER, Mark. The Age of Migration: International Population Movements in the Modern World, p. 79.

${ }^{44}$ KRALER, Albert. Regularisation: A Misguided Option or Part and Parcel of a Comprehensive Policy Response to Irregular Migration?, p. 17.

${ }^{45}$ BROEDERS, Dennis, ENGBERSEN, Godfried. The Fight Against Illegal Migration. Identification Policies and Immigrants' Counterstrategies.

${ }^{46} \mathrm{Na}$ UE, o surgimento de várias propostas que visavam limitar a liberdade dos programas de regularização levaram ao estabelecimento de um "mecanismo de informação mútua" em 2006 (decisão do Conselho 2006/688/CE de 5 de outubro de 2006. Esta decisão é relativa ao estabelecimento de um mecanismo de informação mútua sobre as medidas dos Estados-Membros nos domínios do asilo e da imigração.

47 KRALER, op. cit., p. 20.

48 Têm existido ainda alguns programas de regularização concebidos com propósitos humanitários.

${ }^{49}$ Os migrantes irregulares encontram-se divididos em três categorias principais: migrantes laborais, refugiados e migrantes em trânsito (ibidem).

50 Ibidem, p. 22. 
indivíduos de países terceiros. Estes acontecimentos devem-se a escolhas efetuadas pelos Estados com base em decisões no campo das políticas de imigração. É o Estado que designa quem 'pertence' e quem 'não pertence', traçando linhas de soberania em torno dos indivíduos e estabelecendo normas para que os mesmos possam aceder aos direitos, podendo assim ser considerados ou não cidadãos ${ }^{51}$.

$\mathrm{Na}$ Europa, os Estados são soberanos desde os tratados de paz da Vestefália $^{52}$. A territorialidade e a ausência de agentes externos tornaram-se parte dos Estados-Nação. Consequentemente, as fronteiras surgem como uma das características da soberania dos Estados-Nação, sendo implementadas leis e regulações feitas para os fluxos de imigrantes que querem atravessar fronteiras: "só num mundo ordenadamente dividido em estados-nação, que definem regras explícitas sobre a entrada legal (e consequentemente ilegal) de imigrantes é que existe "migração ilegal'"53.

Foi a partir deste momento que o conceito da "ilegalidade" foi institucionalizado (mesmo apesar de ser uma constante), mas só nos últimos 20 anos assumiu importância na agenda acadêmica ${ }^{54}$ e, principalmente, nas preocupações estatais ${ }^{55}$. Pode-se, assim, concluir que a migração, na perspetiva dos Estados não é um direito das pessoas ${ }^{56}$, uma vez que estes são soberanos e podem escolher, por várias razões, se aceitam ou não a entrada de um determinado indivíduo. E nestas circunstâncias, as pessoas escolhem frequentemente a entrada através de métodos irregulares.

No espírito que esteve na base do Pacto Europeu sobre a Imigração e o Asilo, as medidas de gestão das migrações, do asilo, de proteção e de solidariedade são alvo de atenção, havendo uma aposta acurada, em alguns Estados, em políticas de integração que possam proteger os direitos dos migrantes. A política externa da UE, incluindo as parcerias com outros países e o respeito pela promoção de normas e valores, em espírito de solidariedade e interação, revela-se também parte do plano de ação do Programa de Estocolmo, em aplicação desde 2010.

\footnotetext{
${ }^{51}$ GUILD, Elspeth. Justice and Migration. Metropolis15th International Metropolis Conference. Haia, Holanda, 5 de outubro de 2010.

${ }^{52}$ Ou os Tratados de Münster e Osnabrück.

${ }^{53}$ KRALER, op. cit., p. 5.

${ }^{54}$ ANDERSON, Bridget, RUHS, Martin. Researching Illegality and Labour Migration.

${ }^{55}$ A escolha dos termos para esta entrada não-regular num país indica ou uma posição política de neutralidade ou uma inclinação para essa questão.

${ }^{56} \mathrm{O}$ programa de Estocolmo centra-se na defesa de medidas que promovam a Europa como paradigma da justiça e da proteção dos cidadãos contra o crime, sobretudo o que envolve a criminalidade transnacional, aplicando medidas extraordinárias na fronteira, e de gestão célere de catástrofes. A segurança interna e externa fazem parte de uma estratégia comum e reforçada, o que não impede que o acesso à Europa seja eficiente e ao mesmo tempo seguro, procurando-se para tal reforçar ou implementar serviços simultaneamente de controlo e de proteção.
} 
Mitsilegas ${ }^{57}$ analisa, contudo, o crescente enfoque na criminalização como meio de combate à imigração irregular na Europa, observando de que forma tal se repercute nas Leis Europeias e nas leis nacionais dos Estados-membros em matéria de imigração, até que ponto a lei criminal é adotada para lidar com condutas relacionadas com os fluxos migratórios nas duas esferas e até que ponto as Leis da UE impõem limites à soberania dos Estados e ao seu poder para criminalizar essas mesmas condutas. Esta é uma realidade que se afirma como um transplante daquela que se vive, há mais tempo, nos Estados Unidos da América, conforme expusemos anteriormente, mas que se vive a diferentes intensidades nos vários Estados-membros. É importante não esquecer que, apesar de partilharem a soberania a um nível macro, os Estados-membros mantêm uma quota-parte de soberania intocável, sendo-lhes permitido adotar, dentro de um grau de intensidades variável que decorrem das Diretivas Europeias, matizes de intensidade que se vão repercutir em "liminal laws ${ }^{58 "}$ diferenciadas.

Portugal, por exemplo, destaca-se por uma baixa intensidade de criminalização dos imigrantes, tendo sido considerado, novamente, pelo MIPEX ${ }^{59}$ 2015 como o segundo melhor país em termos de medidas de integração de imigrantes. Foi, ainda, considerado recentemente pelo Institute for Management Development suíço ${ }^{60}$ o Estado-membro com a lei de imigração mais positiva no que concerne a integração de imigrantes na área do trabalho. Tal não deve, no entanto, favorecer olvidar que, em 2012 (Lei 29/2012, de 9 de Agosto), a reformulação da Lei 23/2007, de 04 de Julho, passou a incluir a possibilidade de expulsar de Território Nacional cidadãos estrangeiros que até àquela data eram considerados inexpulsáveis ${ }^{61}$, passando esses indivíduos não nacionais a ser devolvidos a países com os quais não têm qualquer laço familiar, social, económico e até desconhecendo a própria língua.

${ }^{57}$ MITSILEGAS, Valsamis. The Changing Landscape of the Criminalisation of Migration in Europe. The Protective Function of European Union Law, p. 87.

${ }^{58}$ Este conceito foi usado por Juliet Stumpf numa comunicação proferida no congresso anual da "Lawand Society Association", 2015 em Seattle. "Liminal" consiste nas estruturas e processos que operam como lei mas apenas são quasi lei (são postos em prática através de documentos como memorandos) (GUIA, Maria João, PEDROSO, João, FERREIRA, António Casimiro. The stratification of citizenship in Portugal, in the context of the European Union - irregularity and 'crimmigration': roots and dangers).

${ }^{59}$ MIPEX - Migrant Integration Policy Index. Para mais informações, vide < http://www.mipex.eu/>

${ }^{60}$ Este instituto é uma escola de negócios classificada como líder na área da gestão. Para mais informações, consulte <http://www.imd.org >

${ }^{61}$ Artigo 1350 da Lei 29/2012, de 9 de Agosto: “Limites à decisão de afastamento coercivo ou de expulsão. Com exceção dos casos de atentado à segurança nacional ou à ordem pública e das situações previstas nas alíneas c) e f) do n.․ 1 do artigo 134.ํㅡ, não podem ser afastados ou expulsos do território nacional os cidadãos estrangeiros que: a) Tenham nascido em território português e aqui residam habitualmente; b) Tenham a seu cargo filhos menores de nacionalidade portuguesa ou estrangeira, a residir em Portugal, sobre os quais exerçam efetivamente as responsabilidades parentais e a quem assegurem o sustento e a educação; c) Se encontrem em Portugal desde idade inferior a 10 anos e aqui residam habitualmente". 


\subsection{A emergência da criminalização da imigração na União Europeia}

A imigração irregular constitui-se, assim, como um elemento decisivo para a modelagem de políticas 'crimigratórias'. Mais, a realidade da imigração irregular relacionada com o discurso do crime é apresentada como um problema de segurança nacional que os Estados soberanos encaram como necessidade de combater através da regulação e do reforço do controlo interno nas fronteiras, que podem funcionar como canal facilitador da circulação ou como elemento de bloqueio à passagem de migrantes ${ }^{62}$. É neste contexto, que surge a perspetiva da securitização proposta pela Escola de Copenhaga, em que a existência de opções políticas impõe uma legitimação das mesmas através de um "ato discursivo"63 que declara a existência de uma ameaça e que justifica a adoção de medidas extraordinárias de segurança para defender um determinado objeto de referência (seja ele um Estado, uma nação, uma religião). Independentemente da existência real dessa ameaça, é necessário que essa ideia seja aceite e reconhecida pelo público a quem a mensagem se destina ${ }^{64}$, transformando-se numa ameaça "existencial", mais do que num problema normal, o que justifica a construção das fronteiras de acordo com escolhas políticas em relação àquilo que representa, ou não, uma ameaça nacional. Esta política de securitização, segundos os autores, cria condições de segurança no interior, garantindo a proteção em relação ao exterior ${ }^{65}$.

Uma lacuna identificada nos estudos sobre o fenómeno da 'crimigração' por Van der Leun e Van der Woude ${ }^{66}$ é a predominância do recurso à perspetiva jurídica, limitação essa que se propõem ultrapassar, na senda de $A a s^{67}$, redefinindo a 'crimigração' como "o entrelaçar do controlo da criminalidade e do controlo da imigração" e introduzindo na pesquisa a esfera social. À esfera jurídica definida por Stumpf (que identifica a convergência da Lei da Imigração e da Lei Penal, com a aproximação dos respetivos aspetos processuais e aplicação de leis), que as autoras classificam como "manifestações exteriores e visíveis assumidas pelo Estado" ${ }^{\prime 68}$ de forma consciente, junta-se um complexo processo social que contribui para a construção do conceito de criminalidade e de estereótipos que Ihe servem de base. Para as autoras, esta complexidade da análise é essencial para o desenvolvimento de estudos comparativos e interdisciplinares sobre o fenómeno, que em si também é dinâmico e transfronteiriço e que se manifesta de forma diferente em vários países. É, assim, essencial compreender de que

\footnotetext{
${ }^{62}$ MATEUS, Nelson. As fronteiras no seu labirinto: permitir ou bloquear o acesso - As políticas de securitização como Gatekeepers.

${ }^{63}$ BUZAN, Barry et alii. Security: A New Framework For Analysis, p. 26.

64 Ibidem, p. 27.

${ }^{65}$ BIERSTEKER, Thomas. The Rebordering of North America? Implications for Conceptualizing Borders After September 11, p. 153.

${ }^{66}$ VAN DER LEUN, VAN DER WOUDE, op. cit.

${ }^{67}$ AAS, 2011, p. 332 apud VAN DER LEUN, VAN DER WOUDE, op. cit., p. 106.

${ }^{68}$ Ibidem, p. 107.
} 
forma conceitos como criminalidade e imigração são enquadrados e introduzidos na esfera social e política e que tipo de discursos suscitam em ambas, já que são estas esferas que formam a base sobre a qual a dimensão jurídica é construída, para funcionar como uma "arma de controlo social"69.

A este propósito, refira-se o caso das polémicas em torno da criminalização da imigração irregular ${ }^{70}$ na Itália ${ }^{71}$ e o debate suscitado na Holanda com vista à criminalização da imigração irregular, apesar da aplicação da Diretiva do Retorno $^{72}$ em curso naqueles países ${ }^{73}$.

A criminalização do imigrante irregular fere frontalmente os postulados de direitos humanos por desconsiderar a dignidade da pessoa humana ao criar uma norma penal que, a um só tempo, viola o princípio da ofensividade ou lesividade, pela incriminação de atitudes internas que não ultrapassam o âmbito do autor e que não afetam bens jurídicos (crime sem vítima); e fere o princípio da presunção de inocência, valendo-se da consideração de crimes de perigo abstrato, presumindo a culpabilidade do agente ${ }^{74}$.

Não podemos esquecer que atualmente $17^{75}$ dos 28 Estados-membros da União Europeia já criminalizam o comportamento de atravessar irregularmente

69 ibidem, p. 109-110.

${ }^{70}$ As leis italianas sobre imigração sofreram sucessivas alterações, das quais destaco a Lei no 40 de 06/03/1998 (Lei Turco-Napolitana) sobre imigração e estrangeiros em Itália, alterada pela lei no 189, de 30/07/2002 (Lei Bossi-Fini) que introduziu medidas contra o tráfico de pessoas, Centros de Detenção de Migrantes, entre outras medidas e a Lei no 125, de 25/07/2008 que criminalizou a irregularidade dos indivíduos em Itália. "O debate que ocorreu nas cortes judiciárias italianas foi desaguar no Tribunal Constitucional que, pela Decisão no 22/2007, entendeu ser constitucional o dispositivo que impunha a pena de prisão de 1 a 4 anos aos estrangeiros que não respeitassem as ordens de expulsão, permanecendo ilegalmente em solo italiano" (Decreto Legislativo n. 286, de 25 de julho de 1998, in SANTOS, Christian. A criminalização da imigração irregular e os direitos humanos. Os casos específicos de Brasil e Itália, p. 109). Foi então o Decreto-Legislativo no 286, de 25/07/1998, no seu artigo 10-A que passou a prever este crime: "Ingresso e soggiorno illegale nel territorio dello Stato. 1. Salvo che il fatto costituisca più grave reato, lo straniero che fa ingresso ovvero si trattiene nel territorio dello Stato, in violazione delle disposizioni del presente testo unico nonchè di quelle di cui all'articolo 1 della legge 28 maggio 2007, n. 68, è punito con l'ammenda da 5.000 a 10.000 euro. Al reato di cui al presente comma non si applica l'articolo 162 del codice penale".

71 Através da adoção do "Pacto de Segurança", aprovado em 2009 pela Câmara dos Deputados e que passou no Senado (157 votos a favor, 124 votos contra e 3 abstenções). Este foi um percurso trilhado pela Itália há já alguns anos, tendo marcos já referidos a assinalar, como o Decreto Dini e Decreto Conso, ambos adotados em 1995, a lei Turco-Napolitana e a lei Bossi-Fini, já mencionadas (GARCIA, Fernanda Di Flora. Direitos humanos x políticas migratórias: os centros de detenção para imigrantes na Itália), e a recente descriminalização da imigração irregular, em 2014, após um debate intenso na Câmara dos deputados, em 28 de Fevereiro de 2014, transposta pela revogação do arto 10 으, constante no Decreto Legislativo, no 40 de 4 de Março de 2014.

72 A Diretiva do Retorno (a já referida Diretiva 2008/115/CE do Parlamento e do Conselho de 16 de Dezembro de 2008) foi acordada em Agosto de 2008 (e finalizada a 24.12.2010), e prevê o retorno de cidadãos oriundos de países terceiros, fornecendo aos Estados-Membros critérios para os procedimentos no que diz respeito aos direitos fundamentais do ser humano.

73 GUIA, PEDROSO, FERREIRA, op. cit.

${ }^{74}$ SANTOS, op. cit., p. 124.

75 Referimo-nos à Bélgica, à Bulgária, à Croácia, ao Chipre, à Dinamarca, à Estónia, à Finlândia, a 
a fronteira com penas de prisão e/ou com multas, enquanto 8 Estados-membros punem este ato com multas ${ }^{76}$ (ou com prisão, em certas condições de gravidade). Apenas Portugal, Espanha e Malta não punem a entrada irregular com pena de prisão ou com multas, mas o processo de abandono de território é, por lei, iniciado de imediato ${ }^{77}$. Já a permanência ilegal em determinado Estado-Membro é criminalizada com prisão e/ou multa por 10 dos Estados-membros ${ }^{78}$, e por $15^{79}$ com multa, que pode ser transformada em prisão se o indivíduo não puder pagar (medidas que podem implicar o abandono coercivo do território). Apenas Portugal, Malta e França não punem a permanência ilegal, apesar de ser dado início a um processo de retorno do indivíduo, quando este é detetado, ao seu país de origem ${ }^{80}$.

Tal facto implementou ou reforçou o aparecimento de novos espaços europeus, onde os indivíduos não nacionais não conseguem aceder ou efetivar os seus direitos sociais, ficando assim à mercê da crise económica e das decorrências que uma vida marcada pela vulnerabilidade e exclusão social encetam.

A imagem que se pretende construir é a do imigrante enquanto 'inimigo'. Os Estados, preocupados com a agitação do público, tendem a implementar ou a reforçar medidas progressivamente mais restritivas, dificultando a aceitação, a fixação e a integração dos imigrantes. A tolerância, tradicional na Europa no que diz respeito a esse "fluxo de ajudantes e reconstrutores externos", passou à intolerância e os direitos daqueles que procuram melhores oportunidades de vida foram amplamente reduzidos. Dentro deste contexto, alguns comportamentos de imigrantes, como se referiu, foram e tendem a ser criminalizados, o que, na prática, acaba por favorecer a mobilidade, na UE, de determinados indivíduos e dificultar, ou mesmo barrar, a aceitação de outros, potenciando desigualdades e criando uma cidadania europeia estratificada entre os diversos estratos de cidadãos e os "sem direitos".

\section{Conclusão}

Da análise do caso norte-americano e europeu da evolução das políticas, do direito e das práticas, em matéria de imigração, desde os anos noventa, com a criação de tipos legais de crime e a agravação das penas a serem aplicadas a estrangeiros - acrescendo ainda a expulsão e a perda de vários direitos adquiridos

França, à Alemanha, à Grécia, à Irlanda, à Letónia, à Lituânia, ao Luxemburgo, à Roménia, à Suécia e ao Reino Unido.

${ }^{76}$ Referimo-nos à Áustria, à República Checa, à Hungria, à Itália, à Holanda (caso seja declarado "estrangeiro indesejável"), à Polónia, à Eslováquia e à Eslovénia.

77 FRA. Criminalisation of migrants in an irregular situation and of persons engaging with them, p. 4.

${ }^{78}$ Referimo-nos à Bélgica, à Croácia, ao Chipre, à Dinamarca, à Estónia, à Alemanha, à Irlanda, ao Luxemburgo, à Holanda e ao Reino Unido.

${ }^{79}$ Referimo-nos à Áustria, à Bulgária, à República Checa, à Finlândia, à Grécia, à Hungria, à Itália, à Letónia, à Lituânia, à Polónia, à Roménia, à Eslováquia, à Eslovénia, a Espanha e à Suécia.

${ }^{80}$ FRA, op. cit., p. 5. 
-, emerge o novo paradigma da 'crimigração", enquanto política pública, que nasceu da convergência entre a Lei Penal e a Lei da Imigração, sob a influência da "membership theory" ${ }^{\prime 81}$.

Tais políticas, direito e práticas que ameaçam os "Direitos Humanos" estão a ser transplantadas para a União Europeia. Contudo, conforme as matizes que a soberania partilhada entre os Estados-membros na União Europeia permite, as políticas, as legislações e as práticas "crimigratórias" de gestão da imigração irregular podem ser de intensidade mais leve em alguns países (como em Portugal, onde há um enfoque na inclusão e a possibilidade de "regularização permanente" de imigrantes "ilegais"), ou ser de uma intensidade forte em outros países da UE (como se pode verificar a partir dos exemplos mencionados dos Estados-membros que criminalizaram a entrada e permanência de indivíduos em situação irregular com penas de multa e/ou prisão).

\section{Bibliografia}

ALEINIKOFF, Alexander. Theories of Loss of Citizenship. Mich. L. Ver., v. 84, 1986, p. 1471-1490.

ANDERSON, Bridget; RUHS, Martin. Researching Illegality and Labour Migration. Population, Space and Place, v. 16, 2010, p. 175-179.

BIERSTEKER, Thomas. The Rebordering of North America? Implications for Conceptualizing Borders After September 11. In ANDREAS, Peter; BIERSTEKER, Thomas (eds.). The Rebordering of North America. London: Routledge, 2003, p. 153-168.

BROEDERS, Dennis; ENGBERSEN, Godfried. The Fight Against Illegal Migration. Identification Policies and Immigrants' Counterstrategies. American Behavioral Scientist, v. 50, n. 12, 2007, p. 1-18.

BUZAN, Barry; WAEVER, Ole; De WILDE, Jaap. Security: A New Framework For Analysis. London: Lynne Rienner Publishers, Inc., 1998.

CAEIRO, Pedro. Alguns aspectos do Estatuto de Roma e os reflexos da sua ratificação na proibição constitucional de extraditar em caso de prisão perpétua. MPM em Revista, n. 4, 2007, p. 4-13.

CASTLES, Stephen; MILLER, Mark. The Age of Migration: International Population Movements in the Modern World. London: Macmillan, 1998.

CVAJNER, Martina; SCIORTINO, Giuseppe. A Tale of Networks and Policies: Prolegomena to an Analysis of Irregular Migration Careers and Their Developmental Paths. Population, Space and Place, v. 16, n. 3, 2009, p. 213-225.

DEMLEITNER, Nora. Misguided Prevention: The War on Terrorism as a War on Immigrants Offenders and Immigration Violators. Crim. Law Bulletin, v. 40, n. 6, 2004, p. 550-575. ENGBERSEN, Godfried. The unanticipated consequences of panopticon Europe. Residence strategies of illegal immigrants. In GUIRAUDON, Virginie; JOPPKE,

${ }^{81}$ STUMPF, op. cit. 
Christian (eds.). Controlling a new migration world. London: Routledge, 2001, p. 222-246.

ETIENNE, Jean; BLOESS, Françoise; NORECK, Jean-Pierre; ROUX, Jean-Pierre. Dicionário de Sociologia. Lisboa: Plátano Edições Técnicas, 1997.

FRA. Criminalisation of migrants in an irregular situation and of persons engaging with them. European Union Agency for Fundamental Rights, 2014.

GARCIA, Fernanda Di Flora. Direitos humanos x políticas migratórias: os centros de detenção para imigrantes na Itália. In 36 Encontro Anual da Anpocs, Aguas de Lindóia, 2012. Anais do 36 Encontro Anual da Anpocs, 2012.

GIL-ROBLES, Alvaro. Report by Mr Alvaro Gil-Robles, Commissioner for Human Rights on his visit to Portugal, 27-30 Maio 2003 (for the attention of the Committee of Ministers and the Parliament Assembly). Strasbourg: Office of the Commissioner for Human Rights, 2003.

GUIA, Maria João. Imigração, 'Crimigração' e Crime Violento. Os Reclusos estrangeiros e as representações sobre imigração e Crime. Tese de Doutoramento apresentada à Universidade de Coimbra, 2015.

GUIA, Maria João; PEDROSO, João; FERREIRA, António Casimiro (forthcoming). The stratification of citizenship in Portugal, in the context of the European Union irregularity and 'crimmigration': roots and dangers. In VAN DER WOUDE, Maarte; VAN DER LEUN, Joanne; BARKER, Vanessa. A special Issue of Europeanization of Crimmigration. European Journal of Criminology.

HOEFER, Michael; RYTINA, Nancy; CAMPBELL, Christopher. Estimates of the Unauthorized Immigrant Population Residing in the United States: January 2006. US Homeland Security: Office of Immigration Statistics, 2006.

KESSLER, Timothy. A Quebra do Peso Mexicano: Causas, Consequências e Recuperação. Revista de Economia Política, v. 21, n. 3, 2001, p. 121-145.

KILLIAS, Martin. Immigration and Crime: The European Experience. Improving US and EU Immigration Systems. Migration Policy Institute, 2011.

KOULISH, Robert. Entering the risk society: A contested terrain for immigration enforcement. In GUIA, Maria J.; VAN DER WOUDE, Maartje; VAN DER LEUN, Joanne (eds.). Social Control and Justice: Crimmigration in the Age of fear. Haia: Eleven International Publishing, 2012, p. 61-86.

KRALER, Albert. Regularisation: A Misguided Option or Part and Parcel of a Comprehensive Policy Response to Irregular Migration? IMISCOEWorking Paper, 2009.

LABBENS, Jean. Le Quart-Monde, étude sur la condition sous-prolétarienne. Pierrelaye, 1970.

MATEUS, Nelson. As fronteiras no seu labirinto: permitir ou bloquear o acesso - As políticas de securitização como Gatekeepers. O cabo dos trabalhos: Revista Electrónica dos Programas de Mestrado e Doutoramento do CES/FEUC/FLUC, v. 4, 2010.

Migration News, volume 10, n. 3, Julho de 2003. Disponível em: <https:// migration.ucdavis.edu/mn/more_entireissue.php?idate=2003_07>. Acesso em: 
28.01.2015.

MILLER, Teresa. Citizenship \& Severity: Recent Immigration Reforms and the New Penology. Georgetown Immigration Law Journal, v. 17, 2003, p. 611-666.

MITSILEGAS, Valsamis. The Changing Landscape of the Criminalisation of Migration in Europe. The Protective Function of European Union Law. In GUIA, Maria João; VAN DER WOUDE, Maartje; VAN DER LEUN, Joanne (eds.) Social Control and Justice. Crimmigration in an Age of Fear. Haia: ElevenInternational Publishing, 2012, p. 87-114.

PEIXOTO, João. A imigração em Portugal, demografia e dinâmicas. Boletim da Associação Portuguesa de Demografia, n. 3, 2002, p. 1-3.

PIRES, Rui. Atlas of Migrations. Fundação Calouste Gulbenkian, 2010.

RCMI. As Migrações num Mundo Interligado: Novas Linhas de Acção. Relatório da Comissão Mundial sobre as Migrações Internacionais. Fundação Calouste Gulbenkian, Outubro 2005.

SABBATI, Giulio; POPTCHEV, Eva-Maria. Irregular immigration in the EU: Facts and Figures. Briefing. 2015. Disponível em: < http://epthinktank.eu/2015/04/27/ irregular-immigration-in-the-eu-facts-and-figures/>.

SANTOS, Christian. A criminalização da imigração irregular e os direitos humanos. Os casos específicos de Brasil e Itália. Revista da FARN, v. 9. n. 1/2, 2010, p. 101-129.

STUMPF, Juliet. The Crimmigration Crisis: Immigrants, Crime \& Sovereign Power. American University Law Review, v. 56, n. 2, 2006, p. 368-419.

STUMPF, Juliet. States of Confusion: The Rise of State and Local Power over Immigration". North Carolina Law Review, v. 86, n. 6, 2008, p. 1557-1618.

VAN DER LEUN, Joanne; VAN DER WOUDE, Maartje. Uma Reflexão Sobre a Crimigração na Holanda: O Complexo da Segurança Cultural e o Impacto do Enquadramento. Coimbra: CINETS, 2012.

\section{Abstract}

\section{The unsustainable response of "crimmigration" to migrant irregularity: a perspective of the European Union}

The "irregular" legal status of immigrants when entering and continuing in a certain country is a decision of each State, which may choose to criminalize and forbid these actions or to integrate and "regularize" them, allowing access to (some) of the nationals' rights. In the last few years, several states of the United State shave chosen a public policy of "crimmigration", converging criminal law and immigration law, aiming at punishing and deporting immigrants "defined" as irregular. In Europe, "crimmigration" policies, legislations, and practices, transplanted from the United States, have also been recently implemented. However, countries like Portugal moderately accept this tendency, still preferring the inclusion and legislation of "permanent regularization" of immigrants.

Keywords: irregularity, immigrants, crimmigration, criminalization, inclusion. 
A insustentável resposta da "crimigração" face à irregularidade dos migrantes: uma perspetiva da UE

Recebido para publicação em 19/06/2015 Aceito para publicação em 22/10/2015

Received for publication in June, $19^{\text {th }}, 2015$

Accepted for publication in October, 22 $2^{\text {th }}, 2015$

ISSN impresso 1980-8585

ISSN eletrônico 2237-9843

http://dx.doi.org/10.1590/1980-85852503880004507 